\title{
Annealing effect on residual stress of Sn-3.0Ag-0.5Cu solder measured by nanoindentation and constitutive experiments
}

\author{
Xu Long ${ }^{a, *}$, Shaobin Wang ${ }^{\mathrm{a}}$, Yihui Feng ${ }^{\mathrm{b}}$, Yao Yao ${ }^{\mathrm{a}}$, Leon M. Keer \\ a School of Mechanics and Civil \& Architecture, Northwestern Polytechnical University, Xi'an 710072, China \\ b State Key Laboratory of Nonlinear Mechanics, Institute of Mechanics, Chinese Academy of Sciences, Beijing 100190,China \\ ${ }^{c}$ Department of Civil and Environmental Engineering, Northwestern University, 2145 Sheridan Rd., Evanston, IL 60208, USA
}

\section{A R T I C L E I N F O}

\section{Keywords:}

Lead-free solder

Annealing

Residual stress

Nanoindentation

Constitutive behaviour

\begin{abstract}
A B S T R A C T
In this study, residual stress in $\mathrm{Sn}-3.0 \mathrm{Ag}-0.5 \mathrm{Cu}$ lead-free solder after annealing at varying temperature and duration was investigated by nanoindentation and uniaxial tensile experiments. Based on the unloading response of load-penetration depth, the contact stiffness was theoretically calculated and found to be decreased with increasing annealing duration especially at the annealing temperature of $210^{\circ} \mathrm{C}$. Additionally, the effect of residual stress on constitutive behaviour at strain rates of $1 \times 10^{-3} \mathrm{~s}^{-1}, 5 \times 10^{-4} \mathrm{~s}^{-1}$ and $1 \times 10^{-4} \mathrm{~s}^{-1}$ was consistently observed. By correlating residual stress and elastic indentation recovery, it was confirmed that greater contact stiffness is induced by greater compressive residual stress. Therefore, the optimal annealing condition of SAC305 solder is $210{ }^{\circ} \mathrm{C}$ for $12 \mathrm{~h}$, which is believed to minimize the residual stress and stabilize the mechanical property of annealed solder.
\end{abstract}

\section{Introduction}

Solder materials in the electronic packaging industry are evolving to lead-free due to the toxicity of lead to environment and human health as legislated by RoHS [1], among which Sn-3.0Ag-0.5Cu (SAC305) solder is one of the most promising alternatives to the previous tin-lead solder. To achieve a homogenous microstructure and remove residual stress in SAC305 solder materials, an annealing treatment was applied before tests. Ma [2] adopted 10 days of aging at room temperature for specimens obtained by different cooling rates. Qin et al. [3] aged waterquenched specimens for 15 days in the air. Bai and Chen [4] applied the annealing treatment at $187^{\circ} \mathrm{C}$ for $3 \mathrm{~h}$ which was followed by a fully aging treatment at room temperature for more than 20 days. Kim et al. [5] intended to remove residual defects of tensile specimens under different cooling conditions by heat-treatment at $100{ }^{\circ} \mathrm{C}$ for $30 \mathrm{~min}$. For lead-containing solders, which have been extensively studied and applied (e.g. $63 \% \mathrm{Sn}-37 \% \mathrm{~Pb}$ ), various annealing treatments existed with a wide range of temperature $\left(40-150{ }^{\circ} \mathrm{C}\right.$ ) and duration (1-10 h) [6-9]. Apparently, the annealing temperatures and durations in the literature vary significantly for both lead-free and lead-containing solder materials.

The purpose of this study is to explore the effect of annealing condition to remove residual stress and optimize the mechanical behaviour of SAC305 solder materials. By identical annealing treat- ments with different temperatures and durations, samples are prepared for nanoindentation and constitutive experiments. Regarding the measured load-penetration depth responses from nanoindentation, the contact stiffness for different annealing conditions is calculated by curve fitting the unloading response using the Oliver-Pharr model. By correlating residual stress and elastic recovery of indentation, the optimal annealing condition to alleviate residual stress of SAC305 solder is theoretically investigated. The effect of annealing treatment is also discussed for mechanical properties from constitutive experimental results to confirm the conclusion based on nanoindentation. Finally, the relationship between residual stress and contact stiffness is discussed to effectively reflect the annealing effect.

\section{Experimental procedure}

The samples of approximately $10.0 \mathrm{~mm} \times 10.0 \mathrm{~mm} \times 2.0 \mathrm{~mm}$ dimensions for nanoindentation tests were obtained by machining $96.5 \mathrm{Sn}$ 3.0Ag-0.5Cu (in wt\%) bulk solder alloy which was manufactured by Alpha Assembly Solutions to be free of cast in impurities or included oxides. In order to investigate the effect of different temperatures and durations to alleviate residual stress, annealing treatment for the solder samples was performed in an air furnace with a temperature stability of $\pm 1.0^{\circ} \mathrm{C}$. Considering the melting temperature $T_{m}$ of $217^{\circ} \mathrm{C}$ for Sn$3.0 \mathrm{Ag}-0.5 \mathrm{Cu}$ solder, the annealing temperatures were $80^{\circ} \mathrm{C}, 125^{\circ} \mathrm{C}$,

\footnotetext{
* Corresponding author.

E-mail address: xulong@nwpu.edu.cn (X. Long).
} 


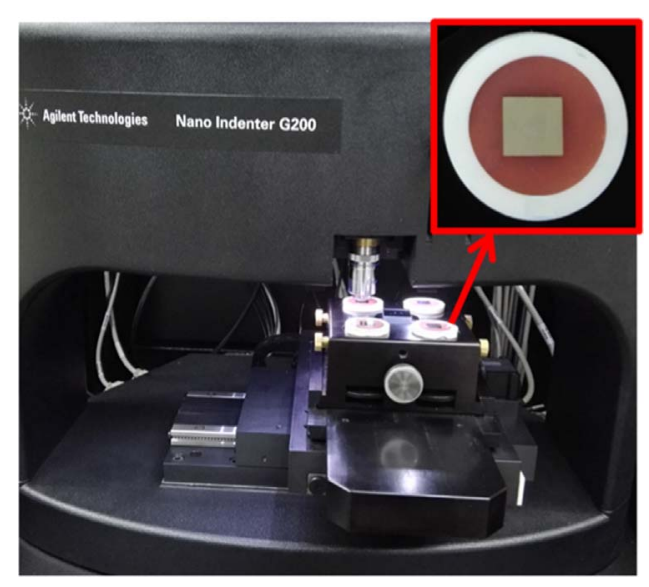

Fig. 1. Indentation instrument and samples of SAC305 solder material.

$165^{\circ} \mathrm{C}$ and $210^{\circ} \mathrm{C}$. The durations were $2 \mathrm{~h}, 6 \mathrm{~h}, 12 \mathrm{~h}, 24 \mathrm{~h}$ and $48 \mathrm{~h}$. After thermal annealing treatment, the samples were mounted in PVC tubes by dental base acrylic resin powder, which solidifies at room temperature without releasing much heat to avoid the influence of temperature to the annealed samples. The solidified acrylic resin owned a satisfactory hardness to provide a matrix for solder samples during indentation tests. The prepared samples were mechanically ground by $\mathrm{SiC}$ abrasive paper, polished with metal diamond suspension of $1.5 \mu \mathrm{m}$ to achieve a mirror-like surface, and eventually ultrasonically cleaned
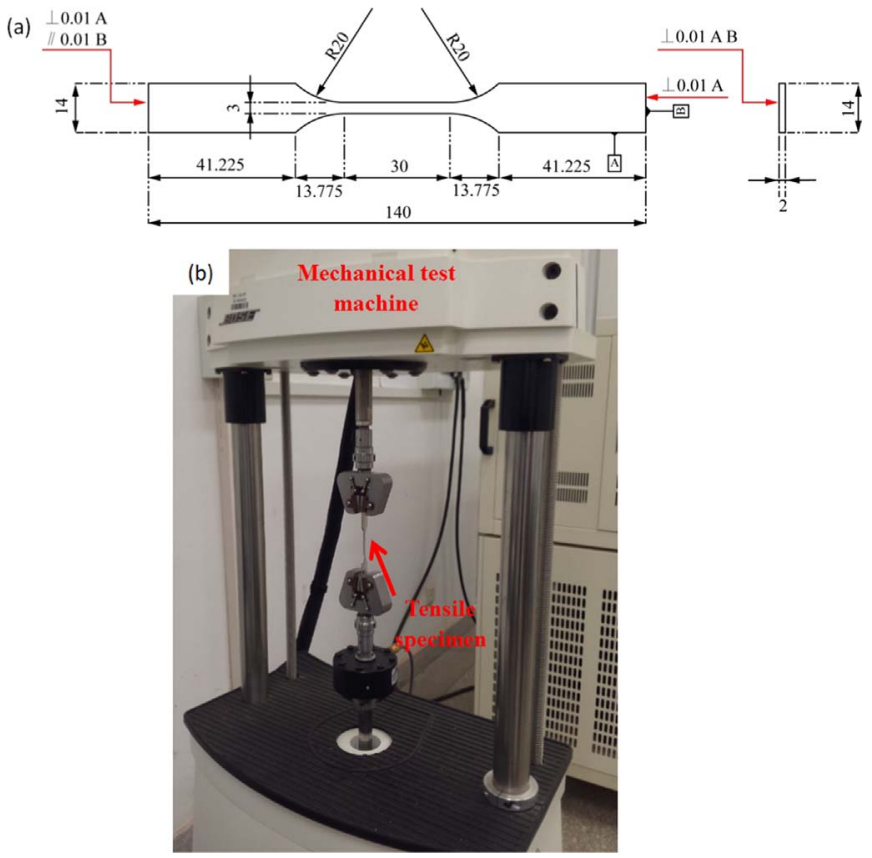

Fig. 2. (a) Dog-bone tensile specimen made of bulk SAC305 solder material; (b) Experimental system for testing tensile behaviour.

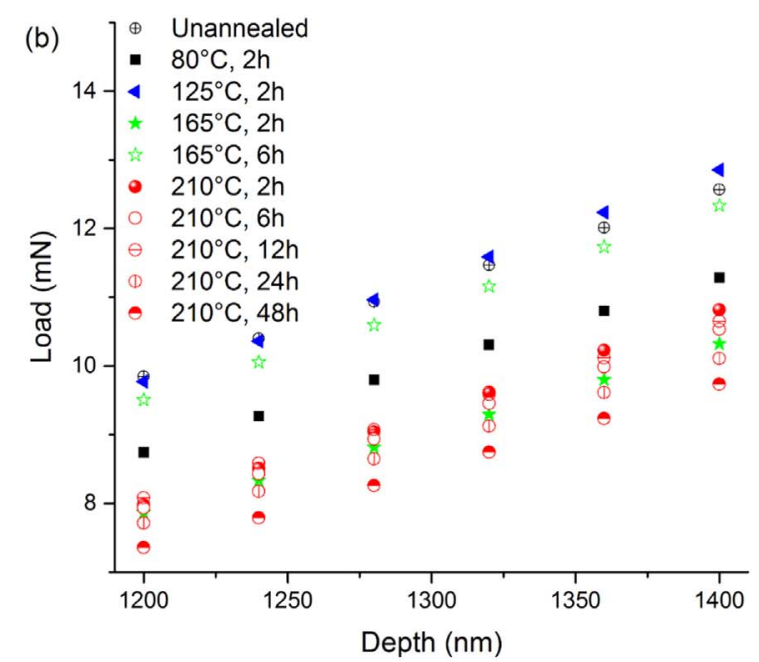

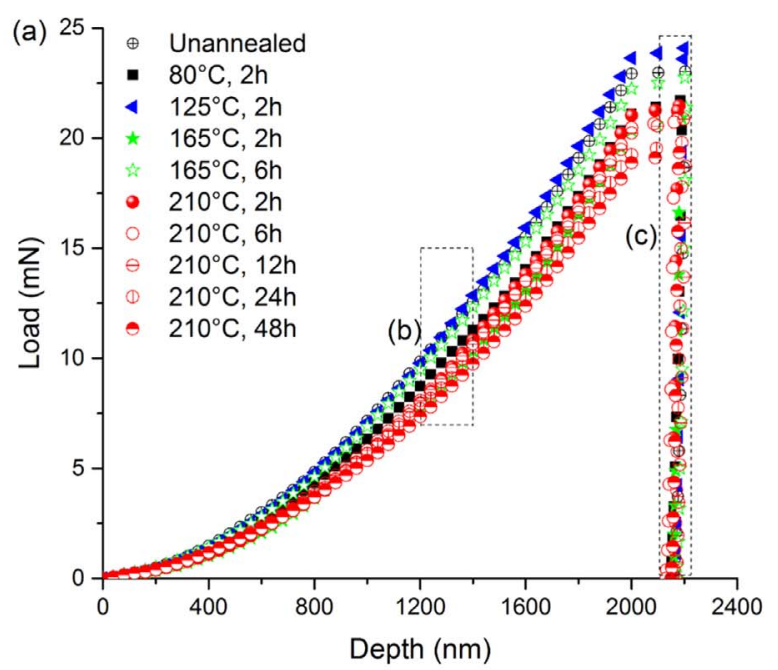

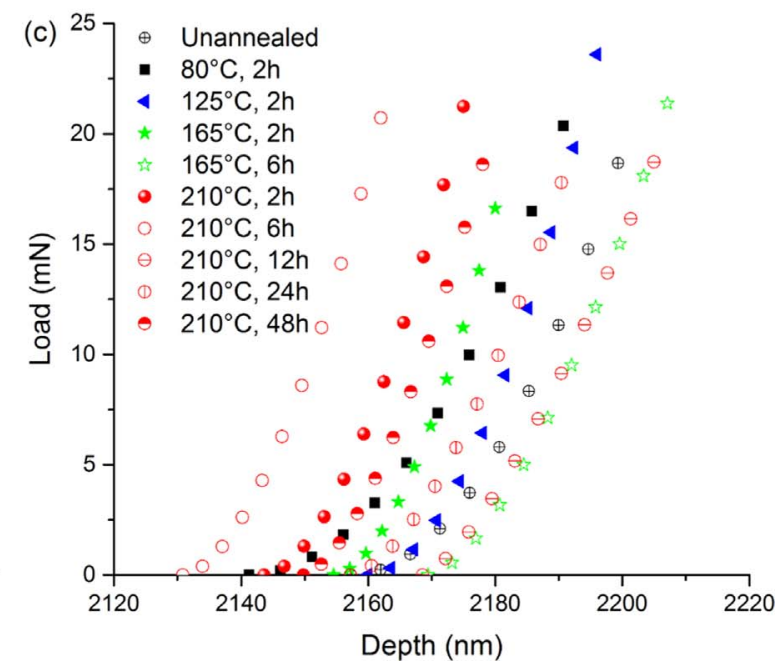

Fig. 3. (a) Load-penetration depth curves; (b) Magnification of loading stage of the curves in (a); (c) Magnification of unloading stage of the curves in (a). 

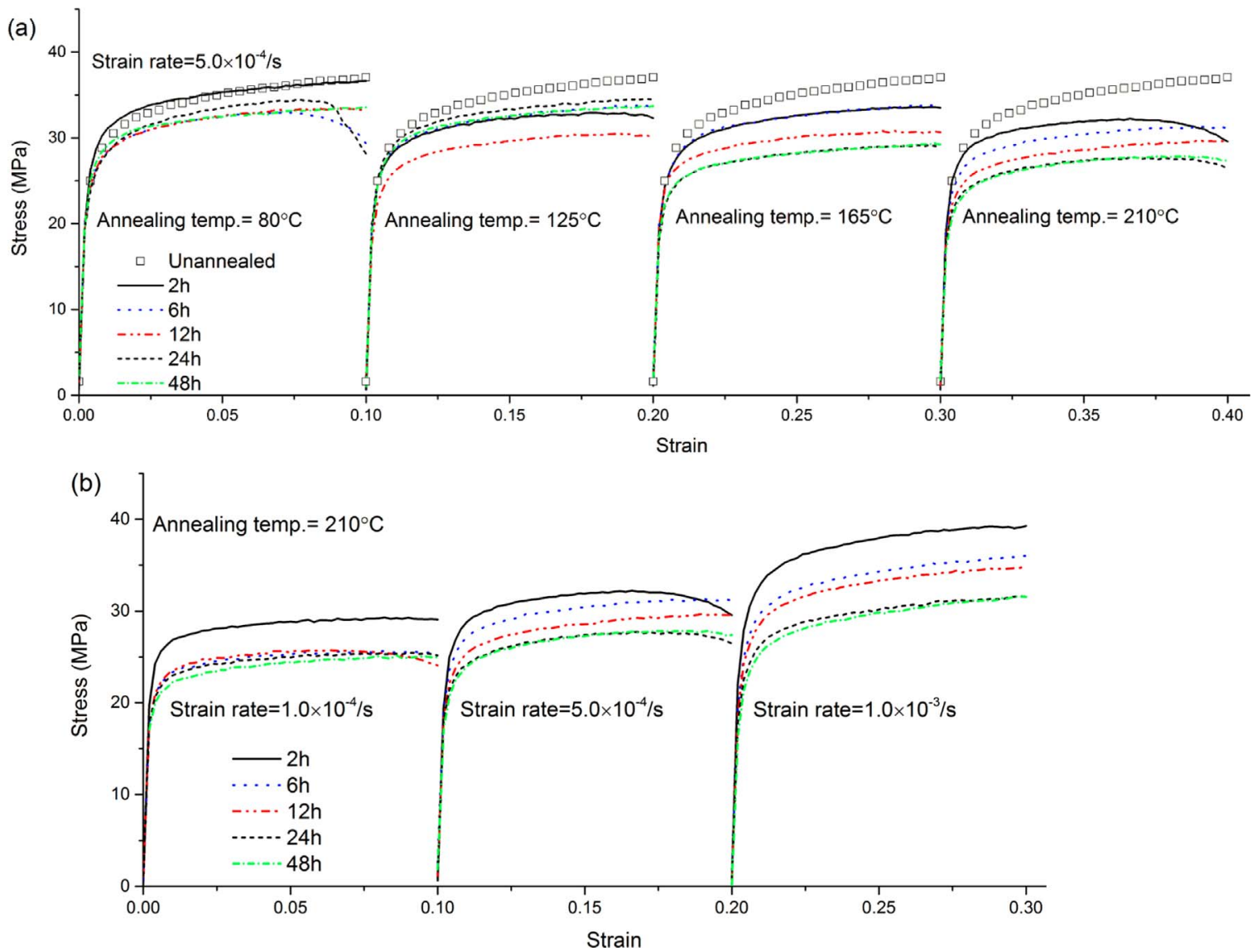

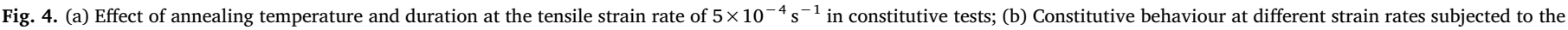
annealing temperature of $210{ }^{\circ} \mathrm{C}$ for varying durations.

in ethanol. After being air dried, the obtained samples were stored at room temperature for more than 10 days to achieve a stable microstructure before indentation tests.

Based on a continuous stiffness measurement technique [10], a Berkovich diamond pyramid indenter in the Nano Indenter G200 by Agilent Technologies was used for an identical pattern of five points on each sample. Experiments of nanoindentation for the control and annealed samples are performed by following the same procedure. Fig. 1 displays the experimental instrument and prepared samples of SAC305 for nanoindentation tests. The obtained load-depth curves were averaged to measure the mechanical property of SAC305 material. The maximum depth for all indentations was set to $2000 \mathrm{~nm}$ under the strain rate of $0.05 \mathrm{~s}^{-1}$ and the temperature of $27^{\circ} \mathrm{C}$. Upon the maximum depth, the indenter was held for $10 \mathrm{~s}$ prior to the unloading stage until the full recovery of indentation. The holding stage is important to alleviate the creep effect and ensure the elastic deformation in the unloading stage [11].

In order to evaluate the annealing effect on the constitutive behaviour of SAC305 solder material, uniaxial tensile tests were performed using the dog-bone type specimen design based on ASTM E8/E8M [12] for tension testing of metallic materials. It is regulated that the thickness should be between $0.1 \mathrm{~mm}$ and $3.0 \mathrm{~mm}$, thus the geometrical details of specimen are correspondingly designed by proportional to the standard one, as shown in Fig. 2(a). Considering objectiveness, the tensile samples were annealed with those for indentation simultaneously. The tensile tests were subjected to strain rates of $1 \times 10^{-3} \mathrm{~s}^{-1}, 5 \times 10^{-4} \mathrm{~s}^{-1}$ and $1 \times 10^{-4} \mathrm{~s}^{-1}$ under displacement control by using Bose ElectroForce 3330 mechanical test machine in Fig. 2(b).

\section{Results}

From nanoindentation experiments, the averaged load-depth curves of five indentations on each sample with different annealing treatments are provided in Fig. 3(a) with Fig. 3(b) and (c) magnifying the loading and unloading stages, respectively. Obviously, the general trend of load-depth curves is similar to each other. According to the magnification for the loading and unloading stages, these loading and unloading curves differ slightly due to the effect of residual stress after thermal treatment subjected to different temperatures and durations. As the annealing process may affect other properties of SAC305 besides residual stress, the underlying mechanism of varied indentation responses remains to be elucidated.

From the constitutive experiments of SAC305 solder, the true stressstrain curves for different annealing treatments and tensile strain rates are provided in Fig. 4. In order to obtain reliable data, the true stressstrain responses are obtained by averaging about four tensile results for each annealing condition and strain rate.

As shown in Fig. 4(a), the ultimate stress of solder tensile samples increased with the increase of annealing temperature. The effect of annealing duration at $210^{\circ} \mathrm{C}$ is more regular than those annealed at lower temperatures (i.e. $80^{\circ} \mathrm{C}$ and $125^{\circ} \mathrm{C}$ and $165^{\circ} \mathrm{C}$ ). With increasing annealing duration, the mechanical property of solder material tends to be stabilized and the duration of $12 \mathrm{~h}$ is sufficient for annealing treatment at $210^{\circ} \mathrm{C}$. Fig. 4(b) shows the stress-strain comparisons of solder samples at the strain rates of $1 \times 10^{-3} \mathrm{~s}^{-1}, 5 \times 10^{-4} \mathrm{~s}^{-1}$ and $1 \times 10^{-4} \mathrm{~s}^{-1}$ so as to confirm the optimal effect of annealing temperature of $210^{\circ} \mathrm{C}$. In addition to strain-rate hardening, the consistent effect of annealing duration at $210{ }^{\circ} \mathrm{C}$ is observed at all strain rates. Because the strain rate for solder material of electronic devices in a normal 


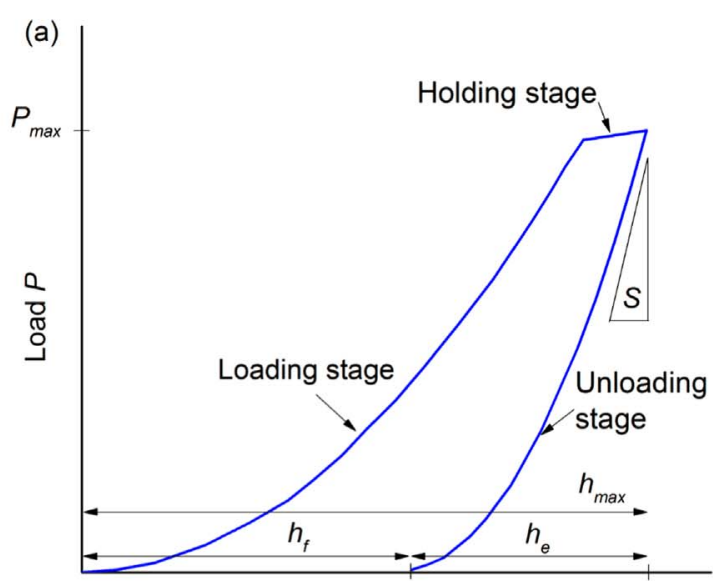

Penetration depth $h$
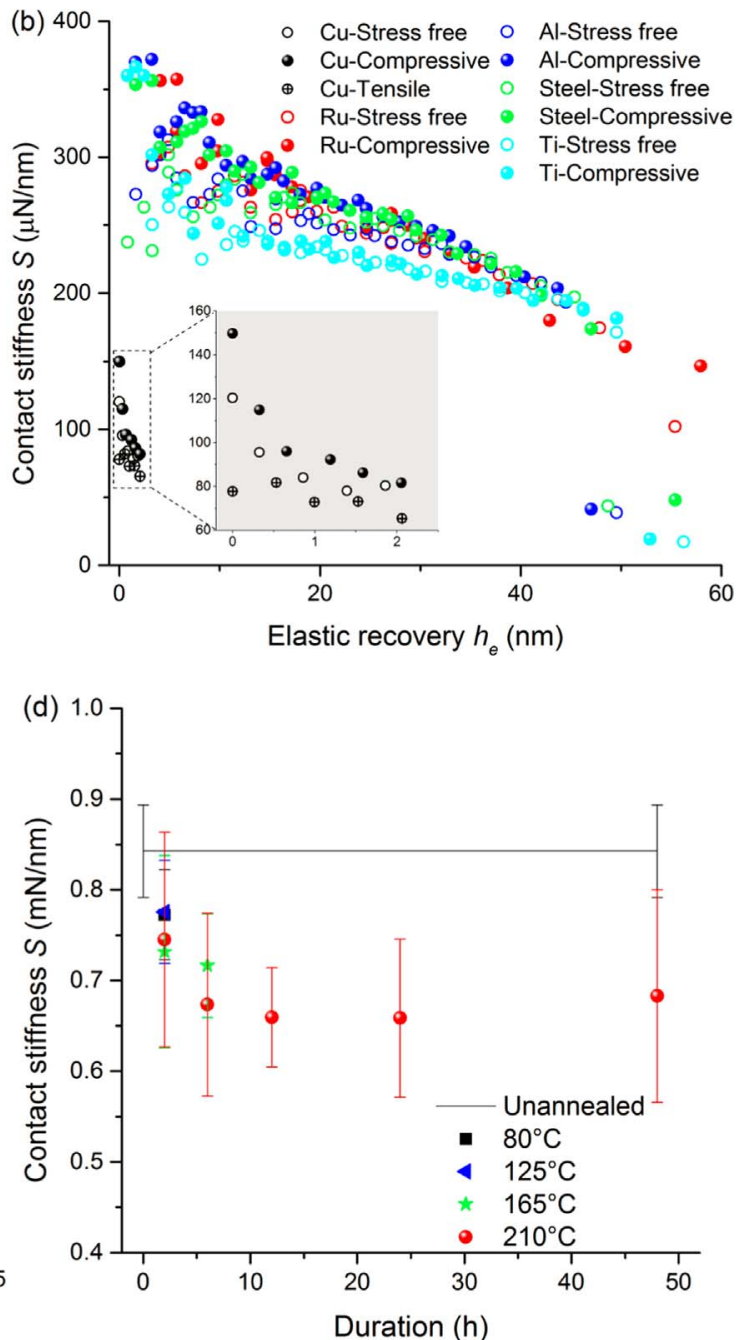

Duration (h)

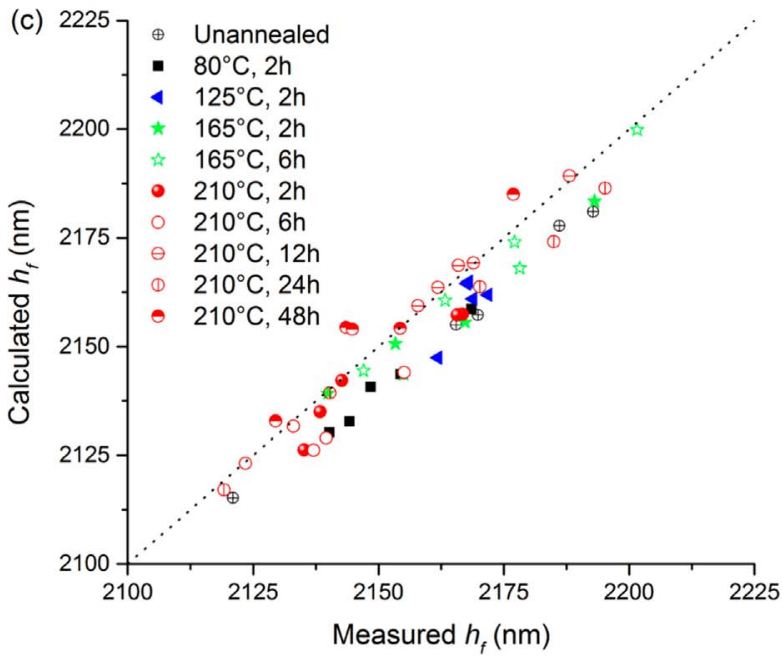

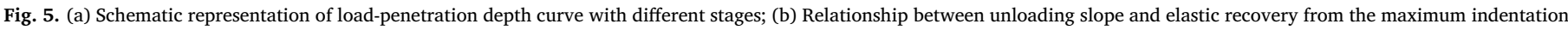

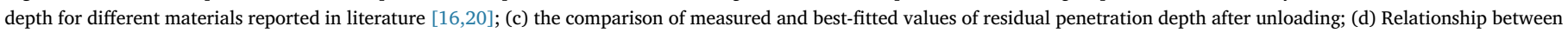
contact stiffness and annealing duration at different annealing temperatures.

working condition is relatively low due to thermal expansion and mechanical connection [13], it can be concluded that the constitutive behaviour of SAC305 solder is stable when the annealing treatment is at $210^{\circ} \mathrm{C}$ for the durations not less than $12 \mathrm{~h}$.

\section{Discussions}

To investigate the effect of annealing condition on residual stress, the unloading path of load-penetration responses in Fig. 3(a) is found to be linear on logarithmic axes and thus can be well depicted by the Oliver-Pharr model [14]. Numerical regression was performed by using the Belehradek model in OriginPro9.0; the adopted fitting function is of the same form as the Oliver and Pharr approximation as below:

$P=\alpha\left(h-h_{f}\right)^{m}$

where $h$ and $h_{f}$ represent the total and residual penetration depths of the indenter. For each load-penetration depth curve, the constant values of $\alpha, h_{f}$ and $m$ are best-fitted based on regression.

By differentiating the load with respect to the maximum indentation depth $h_{\max }$, the contact stiffness $S$ to describe the slope of the unloading path can be calculated as

$S=\left.\frac{d P}{d h}\right|_{h=h_{\max }}=\alpha \cdot m\left(h_{\max }-h_{f}\right)^{m-1}$
As depicted in Fig. 5(a), the shapes of the load-depth curves were affected by residual stress at different stages; compressive residual stress shifts up the loading stage and steepens the unloading stage, and vice versa. This effect of residual stress on the loading stage has been observed in experiments for various types of materials [15-19]. The effect on the unloading stage has been well investigated in experiments for alloys with different crystal structures such as copper $(\mathrm{Cu})$, ruthenium (Ru), aluminium (Al), titanium (Ti) and steel $[16,20]$ as shown in Fig. 5(b). It means that a steeper unloading slope (i.e. a greater value of contact stiffness $S$ ) indicates a greater magnitude of compressive residue stress. The concept of contact stiffness $S$ is thus employed to indicate effectively the magnitude of residual stress in Fig. 3.

Based on numerical regressions and the Oliver-Pharr model in Eq. (1), the parameters to describe the unloading response can be determined. Specifically, Fig. 5(c) shows that the best-fitted values of $h_{f}$ agree well with those measured during indentation, and indicates that the regression calculations are reliable. Fig. 5(d) shows the calculated contact stiffness according to Eq. (2). Higher annealing temperature leads to lower contact stiffness $S$ and the value of $S$ tends to converge with the increase of annealing duration at $210{ }^{\circ} \mathrm{C}$. This phenomenon coincides with the effect of annealing condition as observed in constitutive experiments in Fig. 4. The annealing temperature of $210{ }^{\circ} \mathrm{C}$, lasting for a minimum of $12 \mathrm{~h}$, is believed to be suitable to remove the residual stress and stabilize the microscopic and macroscopic mechanical behaviour of SAC305. 

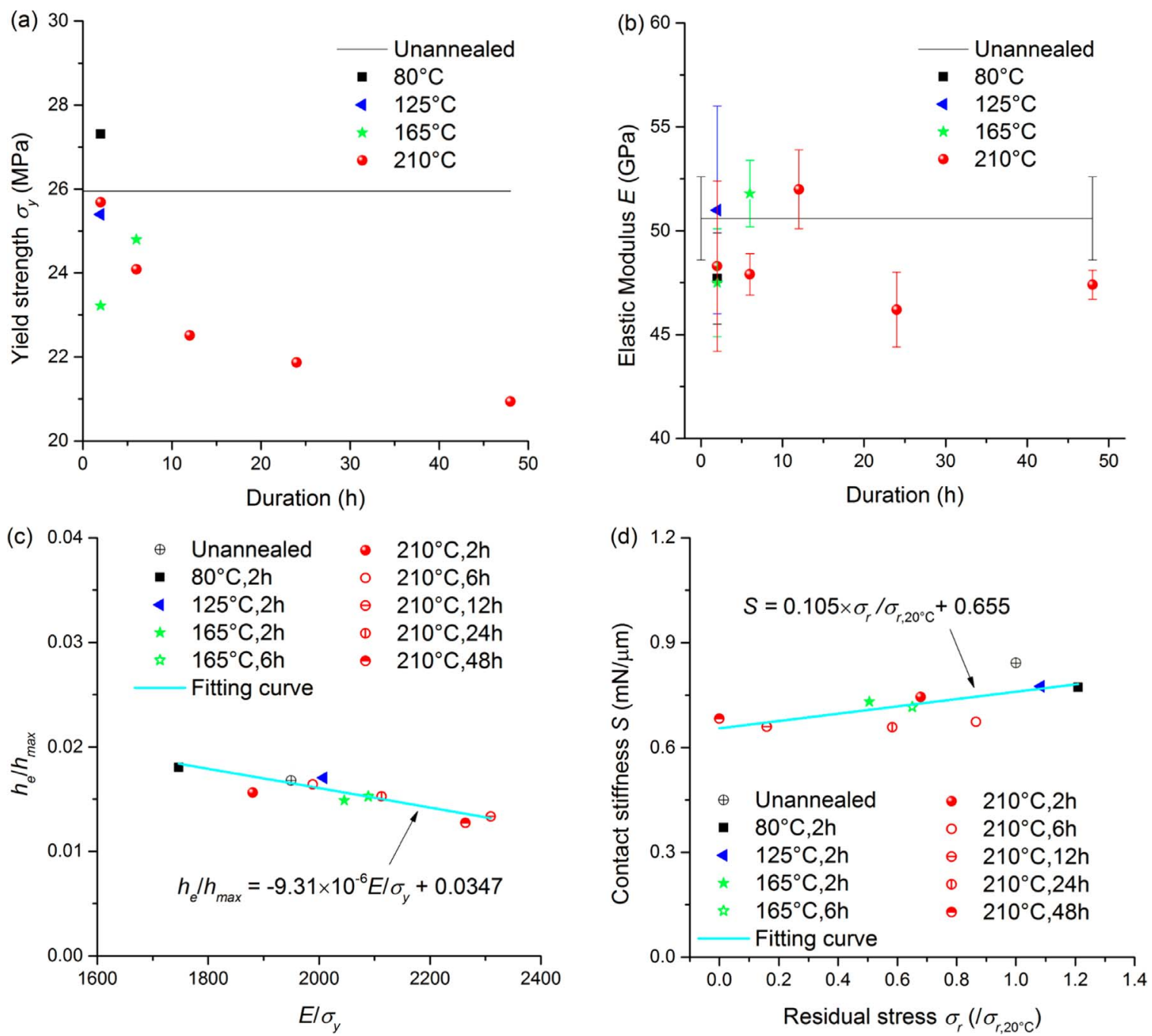

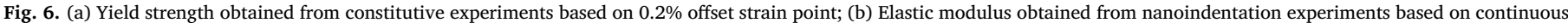

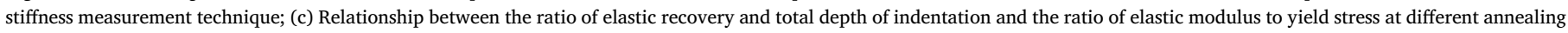
conditions; (d) A positive linear relationship between contact stiffness and residual stress at different annealing temperatures and durations.

Although the rigorous theoretical solution for residual stress of SAC305 solder after annealing treatment is unavailable to date, some numerical analyses have been conducted for elasto-plastic materials [21-23]. Based on extensive experimental and numerical studies, Xu and $\mathrm{Li}[22,24]$ proposed that the elastic recovery of indentation $h_{e}$ (defined as the difference between $h_{\max }$ and $h_{f}$ in Fig. 5(a)) plays an important role to reveal the effect of residual stress $\sigma_{r}$ as shown in Eq. (3).

$\frac{h_{e}}{h_{\max }}=a \frac{\sigma_{r}}{\sigma_{y}}+b$

where $a=10.53\left(E / \sigma_{y}\right)^{-1.25}$ and $\sigma_{y}$ is a yield strength to be determined by independent constitutive experiments in Fig. 4(a). The value of $b$ indicates the linear relationship's intercept when $\sigma_{r}=0$. As it is very difficult to produce a residual stress-free state, the sample after annealing treatment at $210^{\circ} \mathrm{C}$ for $48 \mathrm{~h}$ is assumed to be stress-free in the present study and the value of $b$ is obtained as 0.0127 . This assumed unstressed state is similar to the assumption by other studies to relieve pre-existing residual stress [25].

As there is no definite point on the stress-strain curves in Fig. 4 to indicate where elastic strain ends and plastic strain begins, the $0.2 \%$ offset yield strength at the strain rate of $5 \times 10^{-4} \mathrm{~s}^{-1}$ is defined as the yield strength $\sigma_{y}$ in Fig. 6(a). As shown in Fig. 6(b), the elastic modulus $E$ is determined between the indentation depth of $1000-1100 \mathrm{~nm}$ in
Fig. 3(a) based on continuous stiffness measurement theory [10]. It is found that the average value of elastic modulus based on indentation responses are about 47.5 MPa which is greater than the elastic modulus as measured by constitutive experiments. For such a soft solder material, no extensometer was used in constitutive experiments due to the mounting difficulty without introducing defects at sharp contact locations. The moving distance of clamps in the mechanical test machine is employed to calculate the strain at the gauge length of $30 \mathrm{~mm}$. Therefore, the recorded deformation is greater and the calculated elastic modulus from constitutive experiments is lower than the actual value. On the other hand, due to the intrinsic measurement limitation for materials with pile-up deformation of indentations, the elastic modulus calculated from indentation responses is greater than the actual value. Previous studies in the literature show that the determination of elastic modulus based on nanoindentation depends on the applied strain rate [26], the penetration depth [27] and also the crystallographic orientation [28]. Therefore, further investigations for nanoindentation are required to attain an appropriate indenting condition for an accurate modulus to describe constitutive behaviour. However, it has been verified that the values of elastic moduli from nanoindentation or constitutive experiments will not influence the conclusions drawn from Fig. 6(c) and (d). In the present study, the elastic moduli in Fig. 6(b) measured from nanoindentations are used to calculate the residual stress. 
Fig. 6(c) displays that the value of $h_{e} / h_{\max }$ is almost independent to the ratio of elastic modulus to yield stress $E / \sigma_{y}$ as the slope is negligible. This finding is similar to the experimental and numerical results for materials with low values of $E / \sigma_{y}$ ranging between 75 and 400 [24]. In order to assess the effect of annealing process on the elimination of residual stress, the residual stress is calculated in the following procedure: (1) the yield strength $\sigma_{y}$ is determined by $0.2 \%$ offset strain based on the constitutive responses in Fig. 4(a) and the values are obtained in Fig. 6(a); (2) the value of $h_{e} / h_{\max }$ is measured and calculated based on the indentation responses as shown in Fig. 6(c); (3) the coefficient $a$ is determined based on the empirical relation $a=10.53\left(E / \sigma_{y}\right)^{-1.25}$ with yield strength $\sigma_{y}$ from Fig. 6(a) and elastic modulus $E$ from Fig. 6(b); (4) the coefficient $b$ is calculated as 0.0127 by assuming a residual stress-free for the solder sample after annealing treatment of $210{ }^{\circ} \mathrm{C}$ for $48 \mathrm{~h}$. By substituting the values above into Eq. (3), the residual stress can be obtained for each annealed sample.

It should be noted that the residual stress in the prepared samples are compressive due to the machining process from bulk solder bars. Thus, the residual stress ratio $\sigma_{r} / \sigma_{r, 20^{\circ} \mathrm{C}}$ is always positive, using $\sigma_{r, 20^{\circ} \mathrm{C}}$ as a reference value to represent the residual stress of the unannealed sample. Fig. $6(\mathrm{~d})$ displays that the ratio $\sigma_{r} / \sigma_{r, 20^{\circ} \mathrm{C}}$ has a positive linear relationship with $S$ from Fig. 5(d), which means that greater contact stiffness indicates higher compressive residual stress after the annealing treatment. This finding is consistent with the experimental observations made in Fig. 5(b) and (d). Furthermore, it is clearly seen that compared with other annealing temperatures, the compressive residual stress after annealing treatment at $210{ }^{\circ} \mathrm{C}$ is significantly reduced. The optimal annealing condition is confirmed to be $210^{\circ} \mathrm{C}$ for $12 \mathrm{~h}$ with a balance of residual stress and time consumption.

The scattering in Fig. 6(d) is speculated to result from the assumptions made when deriving Eq. (3) by $\mathrm{Xu}$ and $\mathrm{Li}$ [24], that is, (1) equibiaxial residual stress was applied by prescribing a radial displacement along the outer surface of the specimen prior to the indentation and (2) a constant elastic modulus was used. However, the actual distribution of residual stress was not possible to be exactly identical, based on the measured load-depth responses at the spaced indentation points on the same sample. On the other hand, Fig. 6(b) displays elastic modulus scattering to a certain extent, when the annealing treatment varied, although the scattering may not be due to residual stress [29]. Thus the actual relationships between $h_{e} / h_{\max }$ and $\sigma_{r} / \sigma_{y}$ obtained from experimental measurements may not be strictly linear as postulated in Eq. (3).

\section{Conclusions}

In this study, nanoindentation and constitutive experiments were performed for samples after annealing treatment at different temperatures and durations to investigate the effect of residual stress on the micro and macro mechanical behaviour of SAC305 solder material.

The constitutive behaviour of tensile samples annealed at $210{ }^{\circ} \mathrm{C}$ is more consistent and is induced by alleviation of residual stress, as reflected by load-penetration depth from nanoindentations. Compressive residual stress requires greater penetration force to achieve the same depth compared with the unstressed state, and therefore more local plasticity occurs and less elastic recovery is mobilised during unloading. By using the Oliver-Pharr model to best fit the unloading stage of load-depth responses, the contact stiffness of the annealed sample is found to decrease with the increasing of annealing duration. Moreover, based on theoretical correlation between elastic recovery of indentation and residual stress, a linear relationship between contact stiffness and residual stress is obtained. Essentially, greater contact stiffness is validated to represent greater compressive residual stress, which can be used to reflect the annealing effect of SAC305 solder. Therefore, it is evidently concluded that the annealing treatment of $210{ }^{\circ} \mathrm{C}$ for $12 \mathrm{~h}$ is the optimal condition for SAC305 solder to remove residual stress and stabilize the mechanical behaviour.

Nevertheless, it should be noted that the residual compressive stress induces pile-up deformation around indentations, which may restrict the application of Oliver-Pharr model based on sink-in contact as reported by previous research $[25,30]$. Further investigation is required for the estimation of residual stress in annealed SAC305 solder.

\section{Acknowledgements}

The authors are grateful for the supports provided by National Natural Science Foundation of China (Nos. 51508464 and 11572249) and the Fundamental Research Funds for the Central Universities (No. 3102016ZY017).

\section{References}

[1] European Union, Off. J. Eur. Union, L37, 2003, pp. 19-23.

[2] H. Ma, J. Mater. Sci. 45 (2010) 2351-2358.

[3] F. Qin, T. An, N. Chen, J. Appl. Mech. -T. ASME 77 (2010) 1008.

[4] N. Bai, X. Chen, Int. J. Plast. 25 (2009) 2181-2203.

[5] K.S. Kim, S.H. Huh, K. Suganuma, Mater. Sci. Eng. A 333 (2002) 106-114.

[6] X. Chen, D. Jin, M. Sakane, T. Yamamoto, J. Electron. Mater. 34 (2005) L1-L6.

[7] I. Shohji, T. Yoshida, T. Takahashi, S. Hioki, Mater. Sci. Eng. A 366 (2004) 50-55.

[8] R. Chen, F. Yang, J. Phys. D: Appl. Phys. 41 (2008) 1525-1528.

[9] F.Z. Xuan, S.S. Shao, Q.Q. Chen, Microelectron. Reliab. 51 (2011) 2336-2340.

[10] J. Hay, P. Agee, E. Herbert, Exp. Tech. 34 (2010) 86-94.

[11] G. Xiao, G. Yuan, C. Jia, X. Yang, Z. Li, X. Shu, Mater. Sci. Eng. A 613 (2014) 336-339.

[12] Annual Book of ASTM Standards, American Association State, 2009.

[13] X. Long, X. He, Y. Yao, J. Mater. Sci. (2017) 1-18.

[14] W.C. Oliver, G.M. Pharr, J. Mater. Res. 7 (1992) 1564-1583.

[15] C.A. Charitidis, D.A. Dragatogiannis, E.P. Koumoulos, I.A. Kartsonakis, Mater. Sci. Eng. A 540 (2012) 226-234

[16] L.N. Zhu, B.S. Xu, H.D. Wang, C.B. Wang, Mater. Chem. Phys. 136 (2012) 561-565.

[17] E.R. Olivas, J.G. Swadener, Y.L. Shen, Scr. Mater. 54 (2006) 263-268.

[18] Y.H. Lee, K. Takashima, D. Kwon, Scr. Mater. 50 (2004) 1193-1198.

[19] J.I. Jang, D. Son, Y.H. Lee, Y. Choi, D. Kwon, Scr. Mater. 48 (2003) 743-748.

[20] B.P. Groth, A.B. Mann, Mater. Lett. 89 (2012) 287-290.

[21] S. Suresh, A.E. Giannakopoulos, Acta Mater. 46 (1998) 5755-5767.

[22] Z.H. Xu, X. Li, Acta Mater. 53 (2005) 1913-1919.

[23] M. Mata, M. Anglada, J. Alcalá, J. Mater. Res. 17 (2002) 964-976.

[24] Z.H. Xu, X. Li, Philos. Mag. 86 (2006) 2835-2846.

[25] L.N. Zhu, B.S. Xu, H.D. Wang, C.B. Wang, Mater. Charact. 61 (2010) 1359-1362.

[26] C.-S. Oh, H.-J. Lee, S.-G. Ko, S.-W. Kim, H.-G. Ahn, Sens. Actuators A-Phys. 117 (2005) 151-158.

[27] D. Ma, W.O. Chung, J. Liu, J. He, Sci. China Technol. Sci. 47 (2004) 398-408.

[28] J.J. Vlassak, W.D. Nix, J. Mech. Phys. Solids 42 (1994) 1223-1245.

[29] T.Y. Tsui, W.C. Oliver, G.M. Pharr, J. Mater. Res. 11 (1996) 752-759.

[30] Y.H. Lee, D. Kwon, Scr. Mater. 49 (2003) 459-465. 